
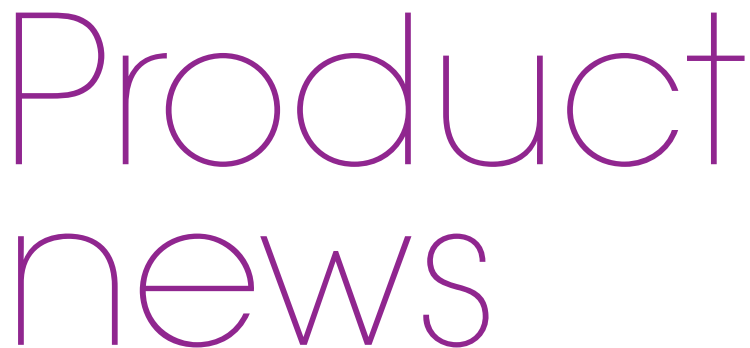

Product news is provided as a service to readers using text and images trom

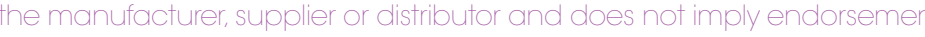

by BD I Team Normal and prudent research should be exercised before

\section{HELP YOUR PATIENTS ADAPT TO DENTURES}

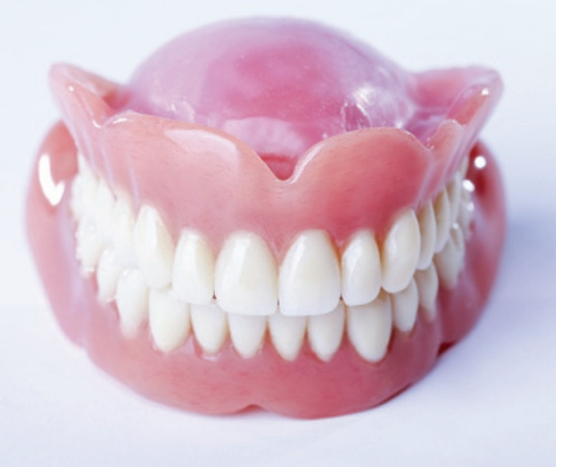

By 2050, 22\% of the global population will be aged over 60 . This increase in the elderly population may present a greater stress on your dental practice and the need for specialist oral health products.

This year the GSK Consumer Healthcare team will be at the Dental Technology Showcase 2016 (DTS) on 22-23 April at
Birmingham NEC, to showcase one of the UK's leading denture brands, Poligrip. Visit stand 630 to find out more about the Poligrip range of cleansers and fixatives and understand how they can help make your patients' denture experience more comfortable.

The stand will feature additional materials to help support your patients in adapting to life with their new dentures and the Poligrip team will be on hand to answer your questions.

Visit the DTS Education Forum for a GSK sponsored lecture session on 'Implants are great, but we still need dentures. The lecturer, Tim Friel, has been a fully qualified Clinical Senior Lecturer for 28 years. He has a clinical interest in all aspects of fixed and removable prosthodontics and dental care of older people with special care requirements - all which will become evident in his presentation.

Visit the DTS Lecture Theatre on Friday 22 April at 12:45 for this unmissable opportunity!

\title{
ADVANCED DENTAL NURSING APPRENTICESHIPS
}

Employer-led, the Advanced Apprenticeship in Dental Nursing presents the perfect opportunity for practices to develop their team and grow their own talent

The 18-month programme is designed to teach apprentices all the skills, knowledge and behaviours they need to fulfil the role of dental nurse successfully.

Candidates complete a level 3 Diploma in Dental Nursing while employers benefit from staff who gain the practical experience they need to become highly engaged and skilled members of the team.

With extensive government funding available to subsidise the cost of training each apprentice, this really is a great opportunity for all to get involved with. Provided by Healthcare Learning and Barnet and Southgate College, London, the majority of the course is delivered through online webinars and eLearning resources, with only a few classroom based workshop days required for added convenience.

Stay one step ahead and find out more about the Advanced Apprenticeship in Dental Nursing today.

For more information or applications contact Healthcare Learning on 0207400 8989 or email qualifications@healthcarelearning.com

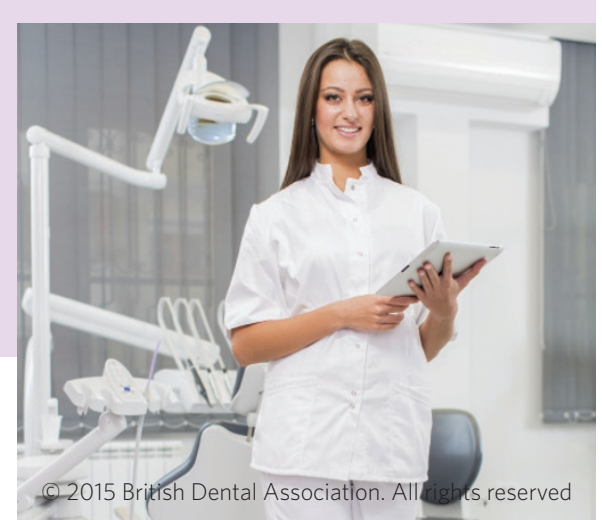

\section{CELEBRATE 31 YEARS OF TALKING POINTS}

The 2016 Talking Points in Dentistry lecture series, presented by the Sensodyne brand, offers tailored sessions for different team members to maximise relevance for the whole dental team.

\section{The personal and social impact of dentine hypersensitivity}

Lecture one: for dentist, hygienists and therapists

Professor Peter Robinson,

Professor Barry Gibson

\section{Dealing with nervous patients}

Lecture two: for dental nurses and other practice staff

Professor Tim Newton,

Brid Hendron

This year's venues

5 May - Hastings Europa, Belfast

12 May - Watford Colosseum, Watford

17 May - GSK House Brentford, London

19 May - ICC Birmingham, Birmingham

Book your tickets now at www.gskdentalprofessionals.co.uk.

If you can't make it to a venue, this year a special bitesize video of the speaker's lectures will be available on www.gskdentalprofessionals.co.uk website after the events.

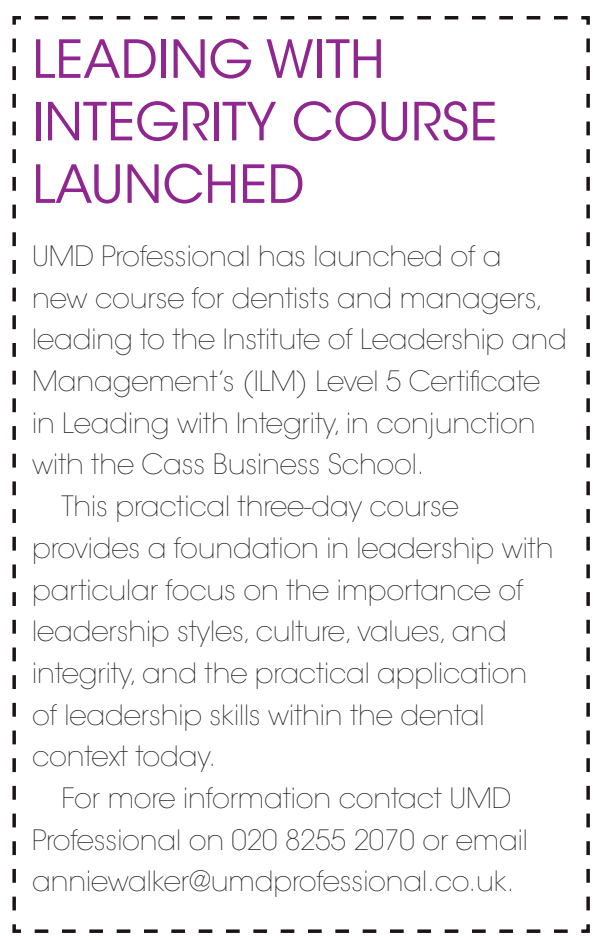

